\title{
Effect of Timing of Circumcision on Sexual Satisfaction and Function
}

\author{
Seyed Reza Hosseini ${ }^{1}$, Mohammad Ghasem Mohseni ${ }^{2}$ \\ ${ }^{1}$ Associate Professor,Department of Urology, Tehran University of Medical Sciences ,Tehran, Iran \\ ${ }^{2}$ Associate Professor,Department of Urology, Tehran University of Medical Sciences ,Tehran, Iran \\ E-mail:rhosseinim@yahoo.com,srhoseini@tums.ac.ir \\ Received January 4, 2011; revised February 15, 2011; accepted February 23, 2011
}

\begin{abstract}
Objectives: Male circumcision is a commonly-performed surgical procedure in the world. Currently, no consensus exists about the role of the foreskin or the effect circumcision on sexual satisfaction. All previous studies have evaluated the effect of adult circumcision on sexual function. In this study, we responded to "Does circumcision timing have different effects on sexual function?" Methods: Based on circumcision timing (receiving circumcision in less than 18 year olds or older than 18 year olds), the participants were divided into two groups. The following data and measurements were investigated: IIEF-5 score, sexual satisfaction, sexual activity [number of sexual attempt/week] and ability to achieve or maintain an erection. Results: Two hundred and fifty cases including 125 men were investigated in each group. The baseline demographic (age, marital status, education, smoking) was similar in the 2 groups. No statistically significant differences were seen regarding their sexual satisfaction $(\mathrm{P}=0.65)$, sexual activity [number of sexual attempt/week] $(\mathrm{P}=$ $0.74)$, ability to achieve or maintain an erection $(\mathrm{P}=0.44),(\mathrm{P}=0.9)$. The total mean IIEF-5 score was 24.21 $+/-1.94$ and $22.23+/-1.12$ in groups 1 and 2 , respectively $(\mathrm{p}=0.5)$. Conclusion: We concluded that the age at which the circumcision is preformed has no effect on the degree of sexual function and satisfaction.
\end{abstract}

Keywords: Circumcision, Timing, Sexual Function

\section{Introduction}

Circumcision is generally undertaken for 3 reasons; first, as a religious ritual; second, as a prophylactic measure against future ailments (for reducing the risk of penile cancer, urinary tract infection, and sexually transmitted diseases); and third, as a means of receiving immediate medical indication.

Beliefs differ on how circumcision affects sexual function satisfaction. [1-7] The relationship between circumcision and sexual function is still in doubt. It ranges from decreased satisfaction and function, to improvement following circumcision. In most previous studies, circumcision was performed due to a medical indication. Few studies, however, have investigated the correlation between circumcision as a prophylactic measure (HIV prevention) and sexual function. [8,9]All mentioned studies have examined the effect of "adult" circumcision on sexual function.

Circumcision is a routine practice in Islamic countries, so we have investigated the effect of circumcision timing on sexual satisfaction and function.

\section{Material and Methods}

From April 2008 to September 2009, all men who were recruited voluntarily from both inpatient and outpatient settings (Sina University Hospital) were investigated. The exclusion criteria were use of drugs with side effects on sexual function, penis anomalies and surgeries, lower urinary tract symptoms including prostatitis, psychological diseases and diseases which significantly impact on sexual function: diabetes, hypertension, hypogonadism, coronary artery disease, and hypercholesterolemia. The Review Board and Ethics Committee of Tehran University of Medical Sciences approved the study. All patients gave written informed consent before participation. Based on circumcision timing (receiving circumcision in less than 18 year olds or older than 18 years), the participants were divided into two groups. Group 1: circumcision was performed in less than 18year olds; group 2: circumcision was performed in older than 18 year olds. 
The International Index of Erectile Function (IIEF) [10] and the routine question were used to evaluate their sexual function. Their sexual performance was evaluated with the Brief Male Sexual Function Inventory (BMSFI) (Appendix).

Chi-square, Fisher's exact test, and independent samples test were used for comparing the variables between the groups. Kolmogorov-Smirnov test was used to demonstrate the normal distribution of measurements in both groups.

\section{Results}

Two hundred and fifty cases including 125 men were investigated in each group. The baseline demographic (marital status, education, smoking) was similar in the 2 groups. Mean patient age was $29.9+/-9$ years and 31.2 $+/-8$ years in groups 1 and 2 , respectively $(\mathrm{P}=0.32)$. The mean score of three sections of the BMSFI and IIEF-5 based on circumcision timing are listed in Table 1. No statistically significant difference was seen regarding their sexual satisfaction $(\mathrm{P}=0.65)$, sexual activity [number of sexual attempt/week] $(\mathrm{P}=0.74)$, ability to achieve or maintain an erection $(\mathrm{P}=0.44)$. The total mean IIEF-5 score was $24.21+/-1.94$ and $22.23+/-1.12$ in groups 1 and 2, respectively $(\mathrm{p}=0.5)$. One sample Kolmogorov-Smirnov test showed that the measurements in both groups have a normal distribution.

\section{Discussion}

Male circumcision is the most commonly-performed surgical procedure in the world. [11]The procedure may be performed to treat an underlying pathological process (therapeutic circumcision) or due to prophylactic, religious, cultural, or social reasons (nontherapeutic circumcision). The glans penis epidermis gradually undergoes some degree of cornification after circumcision. It has been hypothesized that these changes may affect sexual function. Several observational studies of the effect of male circumcision on penile sensitivity, sexual satisfaction and dysfunction have shown conflicting results.

Kigozi and associates concluded that $>98 \%$ of men-

Table 1. Scores of BMSFI andIIEF based on circumcision timing.

\begin{tabular}{cccc}
\hline Test & $\begin{array}{c}\text { Before 18year } \\
\text { olds }\end{array}$ & After 18year olds & P Value \\
\hline Sexual drive & $6.5 \pm 0.2$ & $6.1 \pm 0.4$ & 0.74 \\
Erection & $6.1 \pm 0.5$ & $6 \pm 0.6$ & 0.44 \\
Overall & $3.1 \pm 0.3$ & $3.3 \pm 0.4$ & 0.65 \\
satisfaction & $24.21 \pm 1.94$ & $22.23 \pm 1.12$ & 0.5 \\
IIEF-5 & .
\end{tabular}

BMSFI: Brief Male Sexual Function Inventory; IIEF: International Index of Erectile Function reported sexual satisfaction and normal sexual function after circumcision in this rural population. [9]Krieger et al. demonstrated that adult male circumcision was not associated with sexual dysfunction. On the other hand, circumcised men reported increased penile sensitivity and enhanced ease of reaching orgasm. [8]Senkul et al. [5] surveyed young men of military age in Turkey before and after elective circumcision. They reported that "Adult circumcision does not adversely affect sexual function," although a significant increase in ejaculatory latency times was recorded. Masood et al. argued that penile sensitivity had various outcomes after circumcision. The poor outcome of circumcision considering overall satisfaction rates suggests that when we circumcise men, these outcome data should be discussed during the informed consent process. In their study, penile sensation improved after circumcision in $38 \%(p=0.01)$ but got worse in $18 \%$, and the remainder had no changes. Overall satisfaction was $61 \%$. [2]

To our knowledge, we are reporting the first comparison of male sexual function parameters regarding the age at which the circumcision is preformed. Our study showed that IIEF-5 score was greater 20 in each group. Therefore, circumcision timing (infancy or adult) did not have adverse effect on sexual function. We demonstrated no statistically significant changes in sexual satisfaction, sexual activity and ability to achieve or maintain an erection.

In conclusion, we concluded that the age at which the circumcision is preformed has no effect on the degree of sexual function and satisfaction. However, further studies are essential to document our result.

\section{References}

[1] K. S. Fink, C. C. Carson and R. F. DeVellis, "Adult Circumcision Outcomes Study: Effect on Erectile Function, Penile Sensitivity, Sexual Activity and Satisfaction," Journal of Urology, Vol. 167, 2002, pp. 2113-2165.

[2] S. Masood, H. R. Patel, R. C. Himpson, J. H. Palmer, G. R. Mufti and M. K. Sheriff, "Penile Sensitivity and Sexual Satisfaction after Circumcision: Are We Informing Men Correctly?" Urologia Internationalis, Vol. 75, 2005, pp. 62-66.

[3] S. Collins, J. Upshaw, S. Rutchik, C. Ohannessian, J. Ortenberg and P. Albertsen, "Effects of Circumcision on Male Sexual Function: Debunking a Myth?" Journal of Urology, Vol. 167, 2002, pp. 2111-2127.

[4] D. Kim and M. G. Pang, "The Effect of Male Circumcision on Sexuality," BJU International, Vol. 99, 2007, pp. 619-622.

[5] T. Senkul, C. Iseri, B. Sen, K. KarademIr,F. Saracoglu and D. Erden, "Circumcision in Adults: Effect on Sexual Function," Urology, Vol. 63, 2004, pp. 155-158. 
[6] J. R. Cortés-González, J. A. Arratia-Maqueo, R. Martínez-Montelongo and L. S. Gómez-Guerra, "Does Circumcision Affect Males Perception of Sexual Satisfaction?" Archivos Españoles de Urología, Vol. 62, 2009, pp. 733-736.

[7] M. G. Senol, B. Sen, K. Karademir, H. Sen and M. Saraçoğlu, "The Effect of Male Circumcision on Pudendal Evoked Potentials and Sexual Satisfaction," Acta Neurologica Belgica, Vol. 108, 2008, pp. 90-93.

[8] J. N. Krieger, S. D. Mehta, R. C. Bailey, K. Agot, J. O. Ndinya-Achola, C. Parker C, et al., "Adult Male Circumcision: Effects on Sexual Function and Sexual Satisfaction in Kisumu, Kenya," Journal of Sexual Medicine, Vol. 5, 2008, pp. 2610-2622.
[9] G. Kigozi, S. Watya, C. B. Polis, D. Buwembo, V. Kiggundu, M. J. Wawer, et al., "The Effect of Male Circumcision on Sexual Satisfaction and Function: Results from a Randomized Trial of Male Circumcision for Human Immunodeficiency Virus Prevention, Rakai, Uganda," BJU International, Vol. 102, 2008, pp. 762-763.

[10] R. C. Rosen, A. Riley, G. Wagner, I. H. Osterloh, J. Kirkpatrick and A. Mishra, "The International Index of Erectile Function (IIEF): A Multidimensional Scale for Assessment of Erectile Dysfunction," Urology, Vol. 49, 1997, pp. 822-830.

[11] P. Godbole, P. Duffy, S. A. Boddy, et al., "Management of Foreskin Conditions [Monograph on the Internet]," London: British Association of Paediatric Urologists, 2007. 